\title{
INSTRUCTIVO PARA LA PUBLICACIÓN DE ARTÍCULOS
}

Las personas interesadas en presentar un artículo para publicación en la Revista Jurídica Mario Alario D'Filippo de la Facultad de Derecho de la Universidad de Cartagena deberán acogerse a los siguientes requisitos de forma:

1. Los artículos deben ser inéditos y se deben remitir en original, papel tamaño carta, al editor de la Revista Jurídica Mario Alario D'Filippo de la Facultad de Derecho y Ciencias Políticas de la Universidad de Cartagena o a través de correo electrónico a la dirección: rmarioalario@unicartagena.edu.co En formato Word. (.doc), a doble espacio (inclusive las referencias), por una sola cara y en extensión que no sea inferior a 10 ni supere las 35 páginas. Se recibirán artículos en español.

2. Los artículos siguen un proceso de selección basado en dos criterios: El primero atiende a la tipología del artículo (de acuerdo con las categorías del Publindex de Colciencias); el segundo verifica el cumplimiento de los requisitos formales. Si el artículo no corresponde a ninguna de las categorías establecidas por la Revista o no se ajusta a los requisitos de presentación formal, se devolverá a su autor, y solo se publicará cuando llene los requisitos.

3. Por tratarse de una publicación con arbitraje, los artículos preseleccionados se remitirán a pares evaluadores, quienes se pronuncian sobre los mismos. Recibido su concepto, corresponde al Comité Editorial decidir qué artículos se publican en cada edición.

4. Para cada artículo, La Revista dejará constancia en la primera página de este de la fecha en que fue recibido por el Editor en el correo electrónico de la Revista (rmarioalario@unicartagena.edu.co), así como de la fecha en que se recibió la aprobación del par respectivo.

5. El Comité Editorial otorga prelación a la publicación de artículos de investigación, reflexión o revisión (tipo 1,2 y/o 3 de Publindex de Colciencias).

6. Reglas para la sesión de reseñas:

Se reseñará un libro o un capítulo de libro. Excepcionalmente, por su calidad académica, se podrá publicar una reseña de un artículo científico. 
La reseña debe ser descriptivo-crítica. Se trata de ofrecer al lector un panorama general de lo que se encuentra en la obra reseñada (componente descriptivo) y una opinión académica sobre su calidad y, según el caso, desventajas del texto reseñado (componente crítico).

La reseña no debe ser inferior a tres páginas y no más de seis, atendiendo a las reglas generales para la presentación de contribuciones de la Revista.

Toda reseña será considerada por el Editor de la Revista. En caso de que lo considere necesario, el Editor podrá designar un evaluador externo.

7. Cada autor se compromete a ceder de manera expresa los derechos patrimoniales derivados de la publicación de su obra; para ello deberá diligenciar el formato de cesión de derechos patrimoniales de autor-revista que firmará, digitalizará y enviará al correo electrónico rmarioalario@unicartagena.edu.co

8. La primera página del artículo deberá contener:

Título del artículo: No mayor de 12 palabras

Nombre completo del autor o autores

Sumario de los títulos y subtítulos que componen el artículo, en letra (Arial) tamaño 12

A pie de página del nombre del autor se deberá especificar:

Afiliación institucional

Título o Títulos académicos

Dirección de correo electrónico

A pie de página del título del artículo se deberá señalar: origen de financiación, subvenciones y apoyos recibidos para la realización del artículo.

9. La segunda página debe contener:

a) Resumen en español y en inglés (Abstract), no mayor de ciento veinte (120) palabras que exponga la tesis central del artículo, la metodología utilizada y una aproximación a los resultados y conclusiones arrojadas.

b) Palabras Clave en español y en inglés (keyWords), entre tres y seis palabras, que incluyan los conceptos más importantes que se manejen en el cuerpo del artículo.

10. Instrucciones para la presentación general del artículo:

Se enviarán en archivo .doc Word (versión 2003 o superior) por correo electrónico a rmarioalario@unicartagena.edu.co

Instrucciones para la presentación general del artículo: Use márgenes de $3.0 \mathrm{~cm}$. En cada uno de los lados de la hoja

Numere todas las páginas en la esquina superior derecha 
Escriba todo el artículo a doble espacio y medio

No inserte tabulaciones o espacios extra entre párrafos

No inserte rompimientos de página

Use un tipo de letra común predeterminada (Arial) tamaño 12

11. Enviar por correo electrónico adjunto los archivos originales de figuras o tablas que aparecen en el artículo, es decir, en el programa que fueron elaborados.

12. Es responsabilidad del autor conseguir los permisos y derechos para anexar materiales o ilustraciones provenientes de otras fuentes.

13. Las opiniones expresadas en los artículos publicados en esta Revista son responsabilidad exclusiva de los autores.

14. Estilo de Citas de la Asociación Psicológica Americana (APA) 5ta edición. 


\section{CLÁUSULA DE CESIÓN DE LOS DERECHOS PATRIMONIALES DE AUTOR}

CEDENTE. Yo Ciudadanía № expedida en identificado con la Cédula de Mayor de edad, cedo a

título gratuito a totalidad de los derechos patrimoniales de autor derivados del presente artículo al: CESIONARIO: Revista Jurídica Mario Alario D'filippo de la Facultad de Derecho y Ciencias Políticas de las Universidad de Cartagena. ISSN 2145-6054.

EI CEDENTE declara que el artículo es original y que es de su creación exclusiva, no existe impedimento de ninguna naturaleza para la cesión de derechos que está haciendo, y responde además por cualquier acción de reivindicación, plagio u otra clase de reclamación que al respecto pudiera sobrevenir.

En virtud de la presente cesión, el CESIONARIO queda autorizado para copiar, reproducir, distribuir, comercializar el artículo objeto de la cesión, electrónica o reprográfico, por cualquier medio digital, electrónico o reprográfico, y conserva la obligación de respetar en todo caso los derechos morales del autor, contenidos en el artículo 30 de la Ley 23 de 1982.

Se firma en señal de aceptación a los días del mes de de

Firma

CEDENTE 